\title{
Median nerve ultrasonography examination correlates with electrodiagnostic studies for the diagnosis of moderate to severe carpal tunnel syndrome
}

\author{
Pavel Potuznika, Petr Hosek ${ }^{b}$, Rudolf Kotas ${ }^{a}$
}

\begin{abstract}
Objective. The aim of the study was to investigate the associations of cross-sectional area (CSA) of the median nerve measured by ultrasonography, the median to ulnar nerve ratio (MUR), the median to ulnar nerve difference (MUD) and the ratio of CSA of the median nerve to height squared (MHS) in relation to electrodiagnostic classification of moderate and severe carpal tunnel syndrome (CTS) and thus to identify patients suitable for surgical treatment.

Materials and Methods. A prospective study was conducted in patients aged $\geq 18$ years who underwent both median and ulnar nerve ultrasonography and electrodiagnostic studies (EDS). 124 wrists of 62 patients were examined. The patients' characteristics were acquired through a questionnaire. CTS was diagnosed using EDS and classified according to the guidelines of the Czech Republic Association of Electrodiagnostic Medicine. The CSA of the median nerve and of the ulnar nerve were measured at the carpal tunnel inlet.

Results. Median nerve CSA at the tunnel inlet $\geq 12 \mathrm{~mm}^{2}$ correlates with electrodiagnostic classification of moderate to severe carpal tunnel syndrome. At this cut-off value, the sensitivity of ultrasonography is $82.4 \%$, its specificity is $87.7 \%$, the positive predictive value is $82.4 \%$, the negative predictive value is $87.7 \%$. MUD, MUR and MHS perform worse than the median nerve CSA, as shown by their lower area under the receiver operating characteristic curve.

Conclusions. Ultrasound could help us indicate surgical treatment for CTS, especially in patients with clinical findings. Our results suggest a cut-off value of CSA at the tunnel inlet of $\geq 12 \mathrm{~mm}^{2}$.
\end{abstract}

Key words: carpal tunnel syndrome, median nerve, electrodiagnostic studies, ultrasonography, coss-sectional area

Received: September 17, 2021; Revised: November 19, 2021; Accepted: November 19, 2021; Available online: December 9,2021 https://doi.org/10.5507/bp.2021.068

(c) 2021 The Authors; https://creativecommons.org/licenses/by/4.0/

${ }^{a}$ Department of Neurology, Faculty of Medicine in Pilsen, Charles University, University Hospital Pilsen, Czech Republic

${ }^{b}$ Biomedical Center, Faculty of Medicine in Pilsen, Charles University, Czech Republic

Corresponding author: Pavel Potuznik, e-mail: potuznikp@fnplzen.cz

\section{INTRODUCTION}

Carpal tunnel syndrome (CTS), characterized by compression of the median nerve at the wrist, is the most common entrapment neuropathy ${ }^{1}$. Its diagnosis is usually based on typical clinical symptoms. The estimated annual incidence of CTS per 100000 population ranges from 324 to 542 for women, and 125 to 303 for $\mathrm{men}^{2,3}$. The estimated prevalence of CTS in the general population is $1-5 \%$ (ref. ${ }^{4,5}$ ). Risk factors of CTS include female gender, advanced age, repetitive use of the hand and wrist (e.g., typists, data entry workers, mechanics, carpenters), trauma (fracture or dislocation of the carpal bones), endocrine disorders (hypothyroidism, acromegaly and diabetes), rheumatoid arthritis, and pregnancy.

Concerning the pathogenesis of CTS, the compression within the canal is thought to disturb blood flow and lead to venous congestion and oedema ${ }^{6}$. Prolonged epineural oedema causes fibroblast invasion into the affected tissue and scar tissue formation around the median nerve ${ }^{7}$. Although the ischemic infarction of the nerve clearly occurs, in most instances of compression or entrapment the predominant clinical manifestations are primarily related to pathologic changes in the myelin sheaths and secondary axonal loss directly due to the pressure ${ }^{8}$.
CTS is one of the most frequent reasons for referral for electrodiagnostic studies (EDS), which represent the gold standard for its diagnosis. EDS classifies the severity of CTS to mild, moderate and severe.

Ultrasonography (US) can be used as an alternative to EDS to diagnose CTS. High-resolution US can assess the anatomy of the median nerve and also identify pathologies of the surrounding structures that may compress the nerve. The calculated mean pooled cross-sectional area (CSA) of the median nerve at the wrist was $8.3 \mathrm{~mm}^{2}$ (ref. ${ }^{9}$ ). Median nerve enlargement is the most common parameter used to diagnose CTS on US with a threshold of the median nerve CSA of $\geq 10 \mathrm{~mm}^{2}$ at the tunnel inlet, i.e. at the level of the pisiform bone ${ }^{10}$.

The goal of our study was to explore the potential of US for diagnosis of moderate and severe CTS based on the median nerve CSA, the median to ulnar nerve CSA ratio (MUR), the median to ulnar nerve CSA difference (MUD) and the ratio of the CSA of the median nerve to the patient's height squared (MHS); all of these compared between the moderate to severe CTS and normal/mild CTS EDS findings and thus to identify patients suitable for surgical treatment. Our aim was to establish the most suitable US-based diagnostic parameter and to determine its cut-off value corresponding with the EDS assess- 
ment according to the guidelines of the Czech Republic Association of Electrodiagnostic Medicine.

The secondary goal of this study was to explore statistically insignificant association CSA with age, body height and sex.

\section{MATERIALS AND METHODS}

\section{Patients and controls}

A prospective review of patients aged $\geq 18$ years who underwent both median and ulnar nerve US and EDS was conducted. 124 wrists from 62 patients were examined between March 2019 and February 2020 at the University Hospital Pilsen, Czech Republic. Diagnosis of CTS was made based on typical clinical symptoms supported by a positive EDS finding. Of the 62 patients, 42 were female and 20 male. In our sample there were 10 patients with mild CTS, 30 patients with moderate or severe CTS and 22 healthy controls.

After identifying patients with final EDS diagnosis of CTS, these patients completed a questionnaire to provide data for the assessment of risk factors for CTS including age, sex, repetitive use of hand and wrist, trauma, endocrine disorders (hypothyroidism, acromegaly and diabetes), rheumatoid arthritis and pregnancy.

\section{Electrodiagnostic studies}

All patients underwent EDS on a Keypoint Dantec Electromyography machine. Standardized EDS were performed by an electromyography-certified electrodiagnostician, using surface electrodes and adjustment for skin temperature, which was kept above $33{ }^{\circ} \mathrm{C}$. The ortodromic sensory median nerve conduction velocity, the distal motor latency and the median motor compound muscle action potential were determined. The ulnar nerve was investigated too.

EDS-based CTS severity was classified according to the guidelines of the Czech Republic Association of Electrodiagnostic Medicine. Diagnosis of moderate and severe carpal tunnel syndrome was made if the median sensory conduction velocity (SCV) from 3rd finger was $\leq 38 \mathrm{~m} / \mathrm{s}$ or the sensory nerve action potential (SNAP) was absent and the median distal motor latency (DML) was $\geq 5.3 \mathrm{~ms}$ or the compound muscle action potential (CMAP) was absent ${ }^{11}$.

\section{Ultrasonography}

Median and ulnar nerve US imaging was carried out by a neurologist certified in functional ultrasound neuroimaging who was blinded to the EDS results. A Toshiba Aplio 500 ultrasound machine with a $14 \mathrm{MHz}$ linear-array transducer was used.

Subjects were seated in front of the sonographer during the scan, with the forearm resting on a table in relaxed supination, fingers in semi-flexed position, and the elbow flexed at approximately 60 degrees. The full course of the median and ulnar nerve was inspected in both transverse and longitudinal planes. The median nerve was identified based on its superficial location with respect to the echogenic flexor tendons. The ulnar nerve was identified beside the ulnar artery. CSA of the median (mCSA) and ulnar nerve (uCSA) was measured at the level of the pisiform bone (Fig. 1). MUR was calculated as the ratio of the mCSA to the UCSA, and MUD as the difference between the mCSA and the uCSA. MHS was obtained as the ratio of the $\mathrm{mCSA}$ (in $\mathrm{mm}^{2}$ ) to the square of the patient's height (in $\mathrm{m}$ ).

\section{Statistical analysis}

Standard frequency calculations and descriptive statistics were used to characterize the groups of patients. Because of their significantly non-normal distribution (as reviewed in histograms and using Shapiro-Wilk test), mCSA and uCSA were tested for significantly different values between moderate or severe CTS and controls using Mann-Whitney U test. Correlations between the mCSA or UCSA and individual EDS parameters were analysed using Kendall's tau. Receiver operating characteristic (ROC) analysis was used to assess the discrimi-

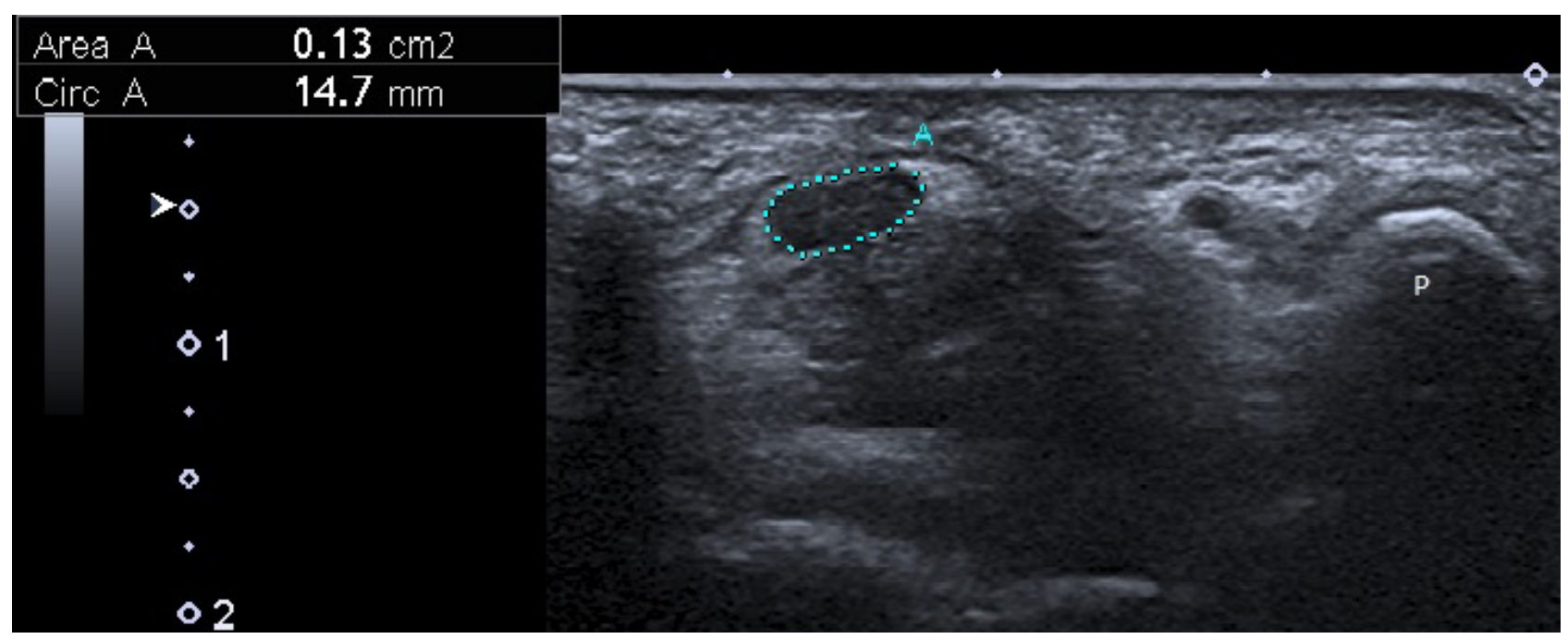

Fig. 1. Cross-sectional area of the median nerve: A- $13 \mathrm{~mm} 2$ (mCSA), P-pisiform bone. 
Table 1. CTS characteristics.

\begin{tabular}{lccc}
\hline Risk factors and characteristics of CTS patients & CTS $(\mathrm{n}=40)$ & Moderate and severe CTS $(\mathrm{n}=30)$ & Mild CTS $(\mathrm{n}=10)$ \\
\hline Male & $13(32.5 \%)$ & $10(33.3 \%)$ & $3(30 \%)$ \\
Female & $27(67.5 \%)$ & $20(66.7 \%)$ & $7(70 \%)$ \\
Age (range) & $60 \mathrm{y}(26-90)$ & $63.5 \mathrm{y}(36-90)$ & $49 \mathrm{y}(26-76)$ \\
Repetitive use of the hand and wrist & $22(55 \%)$ & $17(56.7 \%)$ & $5(50 \%)$ \\
Hypothyroidism & $5(12.5 \%)$ & $4(13.3 \%)$ & $1(10 \%)$ \\
Diabetes mellitus & $7(17.5 \%)$ & $6(20 \%)$ & $1(10 \%)$ \\
Acromegaly & $0(0 \%)$ & $0(0 \%)$ & $0(0 \%)$ \\
Rheumatoid arthritis & $2(5 \%)$ & $1(3.3 \%)$ & $1(10 \%)$ \\
Fractures & $1(2.5 \%)$ & $1(3.3 \%)$ & $0(0 \%)$ \\
Pregnancy & $0(0 \%)$ & $0(0 \%)$ & $0(0 \%)$ \\
No risk factor & $9(22.5 \%)$ & $7(23.3 \%)$ & $2(20 \%)$ \\
More risk factors & $5(12.5 \%)$ & $5(16.7 \%)$ & $0(0 \%)$ \\
\hline
\end{tabular}

native strength of mCSA, MUR, MUD and MHS with respect to the reference EDS-based CTS diagnosis across all possible cut-off points. The classification quality is expressed by a single value of the area under the ROC curve (AUC ROC), with AUC ROC of 1 representing perfectly reliable classification and AUC ROC of 0.5 representing random guessing. Sensitivity and specificity were determined for specific threshold values. Confidence intervals of diagnostic accuracy indicators were calculated according to Agresti and Coull ${ }^{12}$. All reported p-values are twotailed and the level of statistical significance was set at $\alpha$ $=0.05$. Statistical processing and testing was performed in STATISTICA data analysis software system (StatSoft, Inc.2013, Version 12, www.statsoft.com) and Matlab (2019b, MathWorks Inc., Natick, MA, USA).

\section{RESULTS}

The study cohort comprised 51 wrists with moderate or severe CTS. The control group comprised 73 wrists with normal EDS results or mild CTS. The ulnar EDS results were normal.

The mean age of the 40 CTS patients was 60 years (range 26-90 years). Of these 40 patients, 27 were female and 13 male. Age distribution of patients with CTS is indicative of increasing CTS incidence in the older age groups (the mean age of the 22 healthy controls was 43 years, range 23-64 years). The most common cause of CTS was repetitive wrist movements (55\%). The most commonly associated comorbidities were diabetes mellitus $(17.5 \%)$ and hypothyroidism (12.5\%). These characteristics are described in Table 1 . The study cohort is small for accurate assessment of association between EDS results with the etiology of CTS.

We observed a significant swelling of the median nerve at the wrist in CTS. The mCSA at the tunnel inlet in control and mild CTS (median $8 \mathrm{~mm}^{2}$, range $5-15 \mathrm{~mm}^{2}$ ), was significantly (Mann-Whitney U test $P<0.001$ ) smaller than in moderate and severe CTS wrists (median $13 \mathrm{~mm}^{2}$, range $9-21 \mathrm{~mm}^{2}$ ). Detailed analysis of $\mathrm{mCSA}$ with respect to individual EDS parameters showed its significant correlation with both $\mathrm{SCV}$ (Kendall tau $=-0.516, P<0.001$, Fig. 2) and DML (Kendall tau $=0.587, P<0.001$, Fig. 3 ). Also, as seen from the vertical separation of positive CTS wrists and controls in the scatterplots (Fig. 2,3), the diagnosis of moderate and severe CTS was more frequently based on SCV alone (only two CTS wrists with negative SCV finding) in comparison to DML alone (eight CTS wrists with negative DML finding).

In ROC analysis, the mCSA showed a very high ability to distinguish CTS wrists from controls (AUC ROC $=0.930$; Fig. 4). Using the ROC curve, a cut-off mCSA value of $\geq 12 \mathrm{~mm}^{2}$ was identified as providing a good agreement with electrodiagnostic classification of moderate to severe CTS with balanced sensitivity $(82.4 \%$; $95 \%$ CI: $69.2-90.8 \%)$ and specificity (87.7\%; 95\% CI: $77.7-$ $93.7 \%)$. The positive predictive value at this threshold is 82.4\% (95\% CI: 69.2-90.8\%) and the negative predictive value is $87.7 \%$ (95\% CI: 77.7-93.7\%). Alternatively, mCSA at the tunnel inlet of $\geq 11 \mathrm{~mm}^{2}$ shows a higher sensitivity of $94.1 \%$ (95\% CI: $83.2-98.7 \%$ ) with a lower specificity of $83.6 \%$ (95\% CI: $73.0-90.6 \%)$ with respect to the electrodiagnostic classification of moderate to severe CTS.

The ROC analysis of MUR, MUD and MHS for the diagnostic criteria of moderate and severe carpal tunnel syndrome revealed that MUD had the highest AUC of 0.907 , with a suggested cut off value of 7 offering a sensitivity of $92.2 \%$ (95\% CI: 80.7-97.5\%) and specificity of 79.5\% (95\% CI: 68.5-87.4\%) (Fig. 5). The MHS method, with an AUC of 0.903 , provided a sensitivity of $82.4 \%$ (95\% CI: $69.2-90.8 \%$ ) and specificity of $83.6 \%$ (95\% CI: 73.0-90.6\%) at a cut-off value of 4 (Fig. 6). The MUR method showed the worst performance at AUC 0.814, with a possible cut-off value of 2.75 providing a sensitivity of $78.4 \%$ (95\% CI: $64.9-87.8 \%$ ) and specificity of $76.7 \%$ (95\% CI: 65.5-85.2\%) (Fig. 7).

We were using ulnar nerve EDS and CSA as an in- 


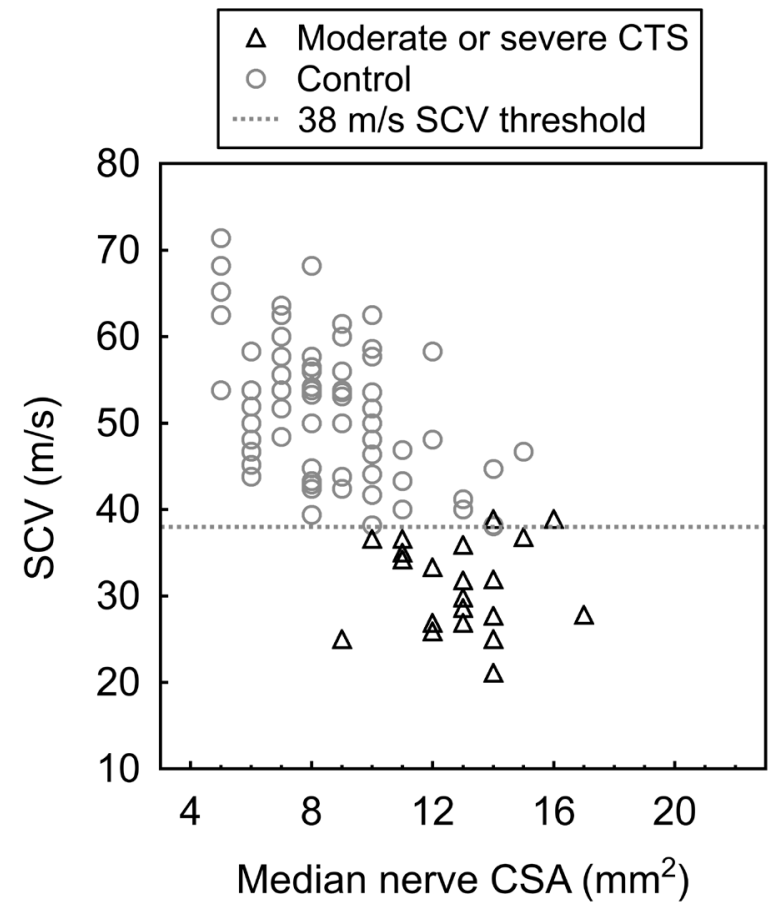

Fig. 2. mCSA correlation with SCV.

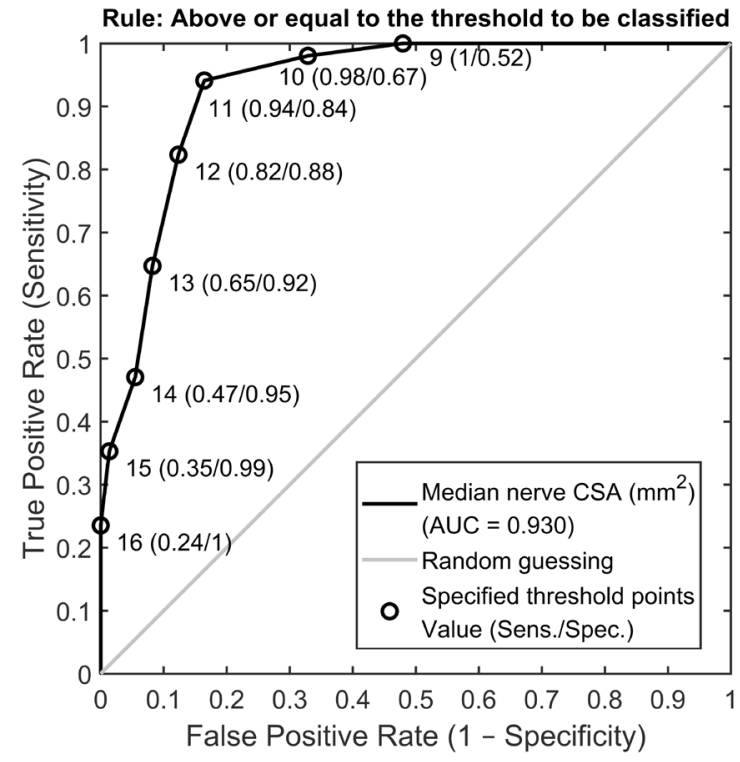

Fig. 4. ROC curve of mCSA.

ternal control. The uCSA showed a borderline, statistically insignificant association with age (Kendall tau $=$ $0.119, P=0.050$ ), and it was weakly associated with body height (Kendall tau $=0.123, P=0.038)$. The uCSA was also significantly associated with sex $(P<0.001)$, which was not the case for the mCSA $(P=0.518)$. Interestingly, uCSA was also significantly associated with both mCSA (Kendall tau $=0.320, P<0.001)$, DML of the median nerve (Kendall tau $=0.234, P<0.001)$, and showed a significant increase $(P=0.001)$ in cases of moderate to severe CTS in comparison to healthy/mild CTS controls. Similarly, all electrodiagnostic parameters of the ulnar nerve also

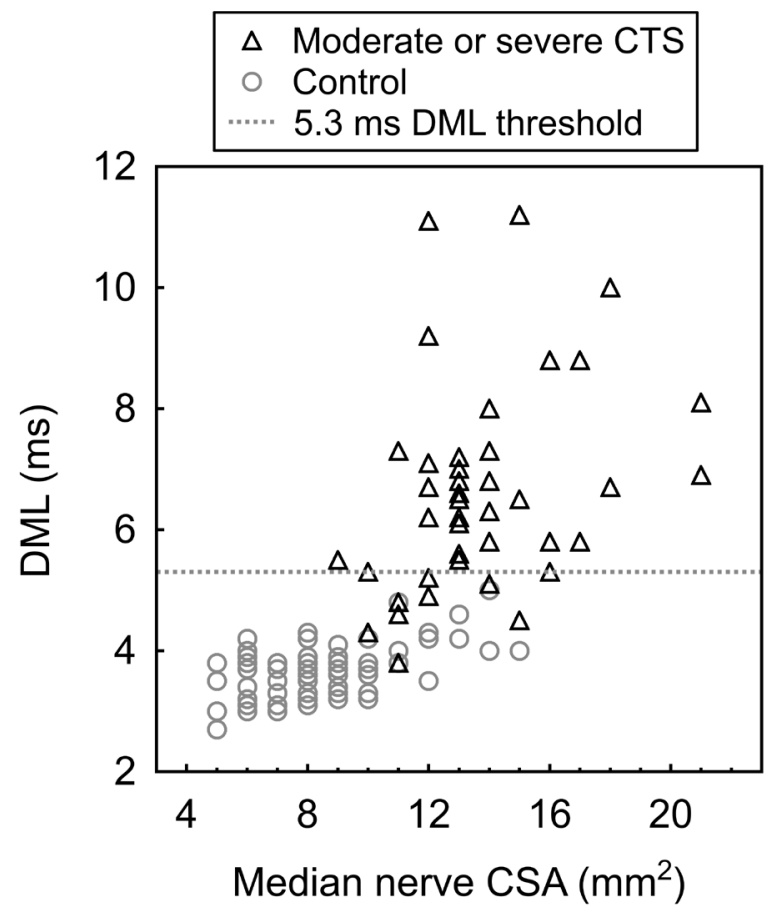

Fig. 3. mCSA correlation with DML.

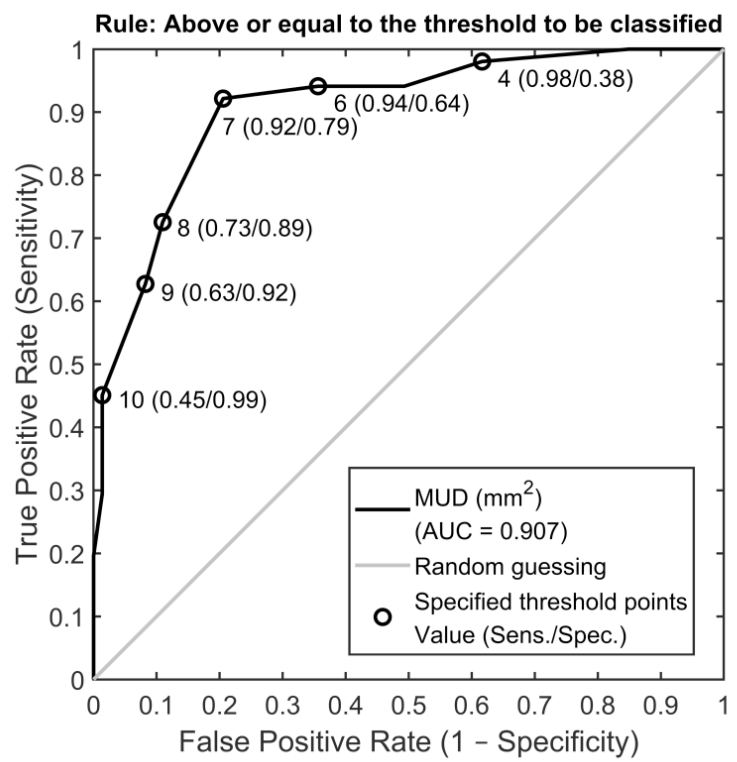

Fig. 5. ROC curve of MUD.

showed significant degradation in moderate to severe CTS in relation to healthy/mild CTS cases, i.e. an increase of DML $(P<0.001)$, and a decrease of both RVS $(P=0.007)$ and CMAP $(P=0.018)$. However, the values of EDS of the ulnar nerve and the uCSA were still normal, all of them were in the physiological range.

\section{DISCUSSION}

An accurate diagnosis of CTS and its severity includes its classification in mild, moderate and severe CTS by 


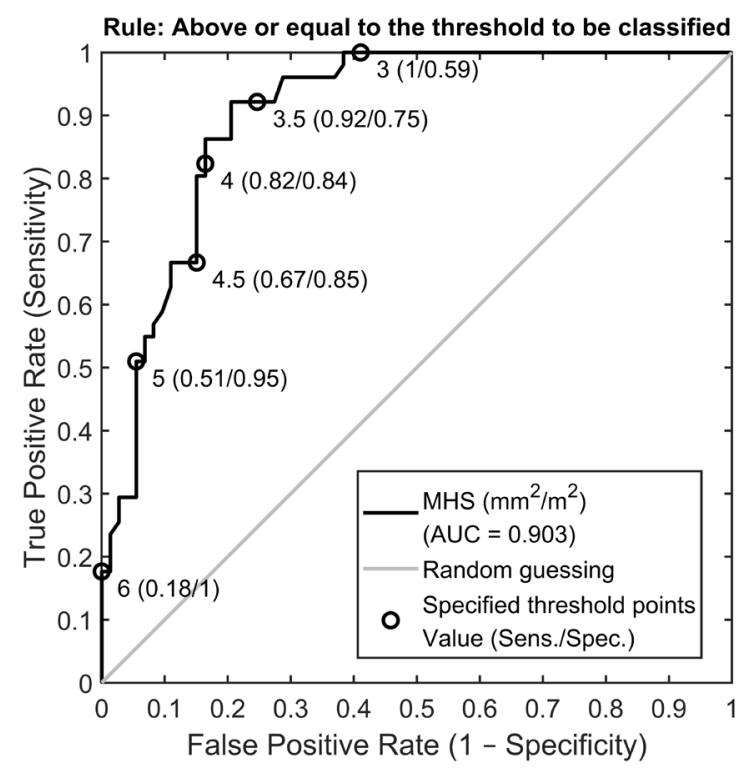

Fig. 6. ROC curve of MHS.

means of EDS - the gold standard for CTS diagnosis. US represents another method of CTS diagnosis. Even though the US does not evaluate the function of the median nerve, it may show its swelling and flattening ${ }^{13}$. The use of US instruments for diagnosis is linked to their board availability, noninvasiveness, shorter evaluation times and cost-effectivity ${ }^{14,15}$. Buchberger et al. were the first to assess the mCSA using high resolution ultrasonography ${ }^{16}$. The ultrasonographic measurement used in CTS diagnosis is the CSA of the nerve at various levels of the carpal tunnel, the flattening ratio, the swelling ratio and increased palmar bowing of the flexor retinaculum ${ }^{17}$. Many authors demonstrated that the CSA at the tunnel inlet had the highest sensitivity and specificity ${ }^{18,19}$, moreover, the measurement at this level was the easiest to perform.

Mean normal values of median nerve CSA at the carpal tunnel inlet have varied among reports, ranging from 8.3 to $10.5 \mathrm{~mm}^{2}$ (ref. $9,10,17,20-24$ ), but electrodiagnostic criteria for CTS classification were varied and sometimes were not well described. Some studies made efforts to diagnose CTS without correlation to EDS or to establish a higher sensitivity than that of EDS.

In a clinical setup however, the important decision point is the distinction between mild and more severe CTS, rather than the detection of its mere presence. The reason being the differences in treatment, which is conservative for mild CTS, but often surgical for moderate and severe CTS. A metaanalysis by Roomizadeh et al. revealed a mean CSA of $13.74 \mathrm{~mm}^{2}$ for moderate CTS (ref. ${ }^{25}$. Moghtaderi et al. suggested that US is a good diagnostic modality for patients with moderate CTS. They accepted a cut-off point of $11.5 \mathrm{~mm}^{2}$ at the tunnel inlet, the sensitivity, specificity, positive predictive and negative predictive value were $83 \%, 90.7 \%, 65.5 \%$ and $55.7 \%$ (ref. ${ }^{26}$ ).

Our findings show that there are clear differences in mCSA between healthy controls or mild CTS cases and cases of moderate to severe CTS. Our results are consis-

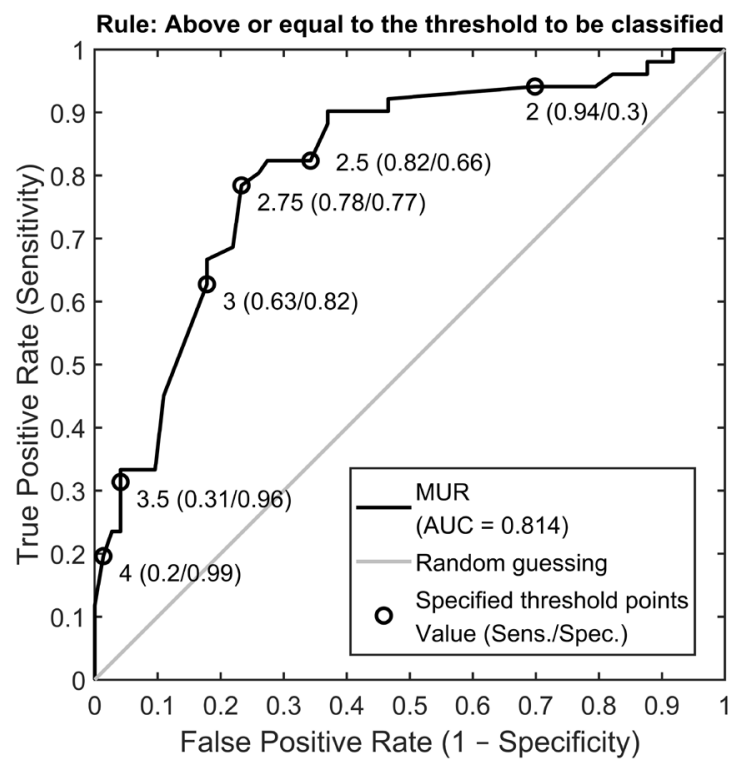

Fig. 7. ROC curve of MUR.

tent with previous studies of US in CTS in showing the enlargement of the median nerve in CTS patients. Our mCSA values correlate with SCV and DML.

We have demonstrated that the CSA $\geq 12 \mathrm{~mm}^{2}$ corresponds well to the electrodiagnostic classification of moderate to severe CTS with good specificity and sensitivity. A positive predictive value and specificity are very important in this situation, particularly if the patient can be a candidate for surgery. Other threshold values can be used as an alternative in clinical settings where different balancing of sensitivity and specificity is required.

Some studies considered that differing demographic and biometric features, such as body mass index, older age or gender may contribute to the range of normal values. Other studies found no significant association between the biometric characteristics of subjects and mCSA $\left(\right.$ ref. $\left.{ }^{27}\right)$. We can say that the range of normal values for mCSA in the literature more likely reflects variations in study design, such as electrodiagnostic criteria and ultrasonographic technique. This conclusion is based upon our observation of the control uCSA, which was not related to age and was only weakly related to body height. We made an attempt to adjust CSA for the potential effects of body height (using MHS), but MHS had worse diagnostic results than CSA alone.

A comparison of the ratio (MUR) or difference (MUD) of the CSA of the median nerve to the ulnar nerve is another way to compensate for the variability of the mCSA due to sex, age and body height. Chang et al. showed that MUR and MUD were significantly larger in patients with CTS than in healthy volunteers. Their ROC analysis of mCSA, MUD, MUR and swelling ratio revealed that MUD had the highest AUC of 0.78, with a clear cut-off value of 5.53 , sensitivity of $84 \%$ and specificity of $69 \%$. The MUR method provided sensitivity of $63 \%$ and specificity of $84 \%$, with a cut-off value of 3.28 and an AUC of 0.75. Their mCSA had an AUC of 0.70, with a cut-off value $10.35 \mathrm{~mm}^{2}$ (sensitivity of $63 \%$ and specific- 
ity of $84 \%$ ) (ref. ${ }^{28}$ ). Eom et al. demonstrated that MUR increased significantly according to the electrophysiological stage. In their study, mean MUR of 2.75 (with an SD of 0.64) was observed in moderate CTS, but even slightly larger MUR of 2.77 (SD 0.81) was reported in mild CTS $\left(\right.$ ref. $\left.^{29}\right)$. They show an increase in MUR between healthy controls and patients with CTS, and also between mild and severe CTS, but there is no significant difference in MUR for mild and moderate CTS.

Our outcomes affirmed Chang 's and Eom 's results.

Yemisci et al. suggest that pathological processes leading to median nerve entrapment in CTS patients may also affect ulnar nerve motor and sensory fibers in the Guyon canal. Only a small proportion of their patients had ulnar nerve conduction abnormalities that exceeded their laboratory limits ${ }^{30}$. These results are similar to our study, which confirmed significant association between moderate and severe CTS and EDS of ulnar nerve and uCSA, with physiological values of EDS of ulnar nerve and $\mathrm{UCSA}$. This explains why the parameters comparing the mCSA with the ulnar nerve (i.e. MUD and MUR) are not more valuable for diagnosis of moderate and severe CTS than mCSA alone, as the uCSA itself is not completely invariant to the changes related to CTS.

\section{CONCLUSIONS}

In conclusion, our data demonstrated that the median nerve CSA had the best diagnostic ability among the tested parameters (excellent AUC ROC of 0.930), followed by MUD and MHS (similar respective AUCs of 0.907 and 0.903), and lastly by MUR (0.814).

This study affirms previous studies in demonstrating the usefulness of US in diagnosing CTS. US is a reliable method for diagnosing moderate to severe CTS. We suggest a cut-off value of the median nerve CSA at the tunnel inlet of $\geq 12 \mathrm{~mm}^{2}$, which had a specificity of $87.7 \%$ and sensitivity of $82.4 \%$ when compared to EDS-diagnosed moderate to severe CTS. The authors recommend using diagnostic ultrasound for moderate and severe CTS, especially for patients with clinical findings, which could be indicated to surgical treatment for CTS. Median nerve CSA at the tunnel inlet, for instance at the suggested threshold value of $12 \mathrm{~mm}^{2}$, could substantially help us indicate surgical CTS treatment. After verification by larger-sample studies, potentially including post-surgery patient followup, US may be used as an alternative diagnostic method to indicate surgical CTS treatment.

Acknowledgements: The work was supported by the Centrum of Clinical and Experimental Liver Surgery project UNCE/MED/006.

Author contributions: PP: ultrasonography, drafting, composition and correction of the article, literature research; PH: data analysis and interpretation, correction and evaluation; RK: electrodiagnostic studies, correction and evaluation.

Conflict of interest statement: The authors declare that they have no conflicts of interest.

\section{REFERENCES}

1. Katz JN, Simmons BP. Clinical practice. Carpal tunnel syndrome. N Engl J Med 2002;346:1807-12.

2. Atroshi I, Englund M, Turkiewicz A, Tagil M, Petersson I. Incidence of physician-diagnosed carpal tunnel syndrome in the general population. Arch Intern Med 2011;171:943-4.

3. Gelfman R, Melton LJ 3rd, Yawn BP, Wollan PC, Amadio PC, Stevens JC. Long-term trends in carpal tunnel syndrome. Neurology 2009;72:33-41.

4. Atroshi I, Gummesson C, Johnsson R, Ornstein E, Ranstam J, Rosén I. Prevalence of carpal tunnel syndrome in a general population. JAMA 1999;282:153-8.

5. de Krom MC, Kester AD, Knipschild PG, Spaans F. Risk factors for carpal tunnel syndrome. Am J Epidemiol 1990;132:1102-10.

6. Glberman R, Hergenroeder P, Hargens A, Lundborg G, Akeson W. The carpal tunnel syndrome: a study of canal pressures. J Bone Joint Surg Am 1981;63:380-3.

7. Lundborg G. Nerve Injury and Repair. Edinburgh, New York: Churchill Livingstone; 1988.

8. Kanta M, Ehler E, Kremláček J, Laštovička D, Adamkov J, Řehák S, Habalová J, Bartoš M. Efekt endoskopické a klasické operace pro syndrom karpálního tunelu. Cesk Slov Neurol N 2008;71/104(2):17379.

9. Fisse AL, Katsanos AH, Gold R, Pitarokoili K, Krogias C. Cross-sectional area reference values for peripheral nerve ultrasound in adults: $a$ systematic review and meta-analysis-Part I: Upper extremity nerves. Eur J Neurol 2021;28(5):1684-91.

10. McDonagh C, Alexander M, Kane D. The Role of Ultrasound in the Diagnosis and Management of Carpal Tunnel Syndrome: A New Paradigm. Rheumatology 2015;54:9-19.

11. Kadaňka Z, Dufek J, Hromada J. Standard elektrofyziologického vyšetření syndromu karpálního tunelu pro potřeby hlášení choroby z povolání. Česká neurologická společnost 2017 [cited 2021 Sep 15]. Available from: https://www.czech-neuro.cz/en/pro-odborniky/ recommended-practices/doporuceni-pro-prakticke-lekare/carpaltunnel-syndrome/ (In Czech)

12. Agresti A, Coull BA. Approximate is Better than "exact" for interval estimation of binomial proportions, The American Statistician 1998;52:119-26.

13. Iannicelli E, Almberger M, Chianta GA, Salvini V, Rossi G, Monacelli $G$, David V. High resolution ultrasonography in the diagnosis of the carpal tunnel syndrome. Radiol Med 2005;110:623-9.

14. Fowler JR, Gaughan JP, Ilyas AM. The sensitivity and specificity of ultrasound for diagnosis od carpal tunnel syndrome: a meta-analysis. Clin Orthop Relat Res 2011;469:1089-94.

15. Chen J, Chen L, Wu L, Wang R, Liu JB, Hu B, Jiang LX. Value of superb mikcovaskular imaging ultrasonography in the diagnosis of carpal tunnel syndrome: Compared with color Doppler and power Doppler. Medicine (Baltimore) 2017;96(21): e6862.

16. Buchberger W, Judmaier W, Birbamer G, Lener M, Schmidauer C. Carpal tunnel syndrome: diagnosis with high-resolution sonography. AJR Am J Roentgenol 1992;159(4):793-8.

17. Azami A, Maleki N, Anari H, Iranparvar Alamdari M, Kalantarhormozi $M$, Tavosi Z. The diagnostic value of ultrasound compared with nerve conduction velocity in carpal tunnel syndrome. International Journal of Rheumatic Diseases 2014;17:612-20.

18. Swen WA, Jacobs JW, Bussemaker FE, de Ward JW, Bijlsma JW. Carpal tunnel sonography by the rheumatologist versus nerve conduction study by the neurologist. J Rheumatol 2001;28:62-9.

19. Wong SM, Griffith JF, Hui AC, Lo SK, Fu M, Wong KS. Carpal tunnel syndrome: diagnostic usefulness of sonography. Radiology 2004;232:93-9.

20. Ha DS, Kim HS, Kim JM, Lee KH. The Correlation Between Electrodiagnostic Results and Ultrasonographic Findings in the Severity of Carpal Tunnel Syndrome in Females. Ann Rehabil Med 2017;41(4):595-603.

21. Fowler JR, Munsch M, Tosti R, Hagberg WC, Imbriglia JE. Comparison of ultrasound and electrodiagnostic testing for diagnosis of carpal tunnel syndrome: study using a validated clinical tool as the reference standard. J Bone Joint Surg Am 2014;96(17):e148.

22. Ooi CC, Wong SK, Tan AB, Chin AY, Abu Bakar R, Goh SY, Mohan PC, Yap RT, Png MA. Diagnostic criteria of carpal tunnel syndrome using high-resolution ultrasonography: correlation with nerve conduction studies. Skeletal Radiol 2014;43(10):1387-94. 
23. Aggarwal P, Jirankali V, Garg SK. Accuracy of high-resolution ultrasonography in establishing the diagnosis of carpal tunnel syndrome. ANZ Journal of Surgery 2020;90:1057-61.

24. Sarraf P, Malek M, Ghajarzadeh M, Miri S, Parhizgar E, Emami-Razav SZ. The best cutoff point for median nerve cross sectional area at the level of carpal tunnel inlet. Acta Med Iran 2014;52(8):613-8.

25. Roomizadeh P, Eftekharsadat B, Abedini A, Ranjbar-Kiyakalayeh S, Yousefi N, Ebadi S, Babaei-Ghazani A. Ultrasonographic Assessment of Carpal Tunnel Syndrome Severity: A Systematic Review and MetaAnalysis. Am J Phys Med Rehabil 2019;98(5):373-81.

26. Moghtaderi A, Sanei-Sistani S, Sadoughi N, Hamed-Azimi H. Ultrasound evaluation of patients with moderate and severe carpal tunnel syndrome. Prague Med Rep 2012;113:23-32.
27. El Miedany YM, Aty SA, Ashour S. Ultrasonography versus nerve conduction study in patients with carpal tunnel syndrome: substantive or complementary tests? Rheumatology (Oxford) 2004;43:887-95.

28. Chang YW, Hsieh TC, Tzeng IS, Chiu V, Huang PJ, Horng YS. Ratio and difference of the cross-sectional area of median nerve to ulnar nerve in diagnosing carpal tunnel syndrome: a case control study. BMC Med Imaging 2019;19:52.

29. Eom Yl, Choi MH, Kim YK, Joo IS. Sonographic findings in the ulnar nerve according to the electrophysiologic stage of carpal tunnel syndrome. J Ultrasound Med 2015;34(6):1027-34

30. Yemisci OU, Yalbuzdag SA, Cosar SNS, Oztop P, Karatas M. Ulnar nerve conduction abnormalities in carpal tunnel syndrome. Muscle Nerve 2011;44:352-7. 